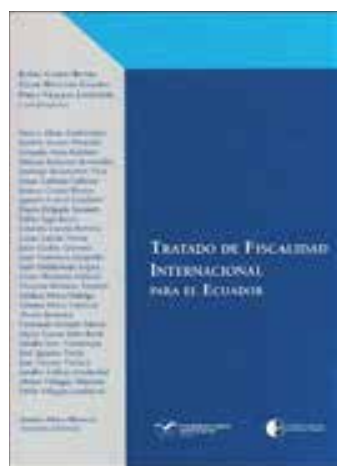

\section{Tratado de FiscaLidad InTERNACIONAL PARA EL ECUADOR}

\author{
Romeo Carpio Rivera, Cesar Montaño Galarza, \\ Pablo Villegas Landázuri (coords. 2019). \\ Universidad Andina Simón Bolívar e \\ Instituto Ecuatoriano de Derecho Tributario: Quito.
}

Dr. Darío Velástegui Enríquez

Velástegui-Abogados V Legal Cía. Ltda., Quito, Ecuador

La obra que hoy es analizada para recomendación de todos los interesados en el derecho tributario internacional y, en fin, para todos y cada uno de los amantes de la tributación internacional, engloba temas de relevancia en materia tributaria, para colocarnos al nivel de la doctrina internacional. Obras de esta envergadura no han sido creadas en el Ecuador hasta ahora, es decir, este libro sin duda alguna ayudará al desarrollo de la academia y a la práctica profesional tributaria internacional, tomando en cuenta el aporte desinteresado de más de treinta escritores nacionales y extranjeros expertos en fiscalidad internacional.

Para empezar, de acuerdo con su tabla de contenidos, la obra se compone de tres temas de mucho valor académico y doctrinario en materia tributaria internacional: 1.- Temas Generales de Fiscalidad Internacional; 2.- Mecanismos contra la evasión y elusión fiscal internacional; y, 3.- Tributación de sectores económicos. En búsqueda de pretender abordar estos temas de tanto interés, se procurará mantener en esta reseña el mismo orden lógico sobre el que se construye esta importante obra. En tal virtud, si bien no haré un análisis tema por tema, trataré de recoger de manera resumida y técnica lo importante de todo lo escrito por los autores, como aporte para la comunidad en materia tributaria internacional, acompañada de un análisis crítico de esta obra.

El trabajo académico doctrinario genera un valor conceptual que conlleva al conocimiento de: conceptos básicos en materia de fiscalidad internacional, sus fuentes, los tratados internacionales suscritos por el Ecuador con otros países para evitar la doble imposición de sus nacionales o residentes, entre otros aspectos. Determinar la importancia académica y profesional de este trabajo requiere trascender la esfera conceptual tributaria para poder entender de adecuada manera esta rama tan importante del derecho tributario, pero que, sin duda alguna es árida en su entender, aunque no es nueva en el establecimiento de las relaciones tributarias de los Estados - nacionales y residentes. Se puede determinar con claridad que todos estos elementos son adecuados al nacimiento de la relación jurídico-tributaria.

Los aportes de los especialistas en materia de fiscalidad internacional, al realizar criticas importantes al régimen actual y a las correspondientes políticas tributarias, hacen de esta obra, sin lugar a duda, un elemento obligatorio de consulta para los estudiantes y estudiosos del derecho tributario.

La concepción de los convenios para evitar la doble imposición se torna en uno de los ejes principales para generar discusión respecto de su aplicación y de los abusos que

\footnotetext{
${ }^{1}$ Docente en la Universidad Andina Simón Bolívar, Ecuador; Universidad Indoamérica, Ecuador. Correo electrónico: dvelastegui@velasteguiabogados.com
} 
pueden cometer los soberanos o sujetos activos de las obligaciones tributarias. Sin embargo, como no puede ser de otra manera, se advertirá que, ciertos comportamientos de los sujetos pasivos llamados a extinguir las obligaciones tributarias generadas en los países contratantes, hacen ineludible regularlos. La solución indiscutible para frenar los abusos y malas prácticas de cualquiera de los sujetos de las obligaciones tributarias surge en la discusión y negociación de cada una de las cláusulas contenidas en los convenios para evitar la doble imposición.

Es necesario enfatizar que la obra hace una parada obligatoria a la realidad del caso ecuatoriano frente a las reglas generales de la fiscalidad internacional. El establecimiento de políticas fiscales, en las que se evidencia lo ventajoso que resulta la suscripción de convenios internacionales para evitar la doble imposición, genera un reflejo conceptual en el análisis de lo conveniente de las políticas de la nación más favorecida, contenidas en las cláusulas en favor del país que concede el tax sparing o el matching credit. Estas políticas y cláusulas se presentan como un ejercicio de atracción de capital para favorecer procesos de inversión con la generación de estímulos fiscales contenidos en beneficios, ya sean exoneraciones o deducciones impositivas.

No es menos cierto que, para poder validar un convenio que evite la doble imposición, es necesario realizar el correspondiente análisis de la legislación interna de cada uno de los países contratantes, las estructuras de los CDIs y los objetos que conllevan esta necesidad. En la obra se evidencia constantemente la importancia de la revisión de la normativa interna en materia tributaria para, de esa forma, precautelar el principio de reserva legal y también el respeto al orden jerárquico de las normas previsto en la Constitución de la República del Ecuador.

Existen constantes recomendaciones de los autores que confluyen en que es imprescindible que cada Estado inicie el ejercicio de establecer una política de negociación de convenios para evitar la doble imposición. Para ello, es importante destacar que en el caso ecuatoriano existen disposiciones constitucionales que son mandatorias a la hora de la estructuración de adecuadas políticas económicas y fiscales. Es decir, se debe partir de la aplicación y respeto de la legislación interna.

El análisis de los casos ecuatorianos, claramente identificados por valiosos académicos y expertos ecuatorianos en temas de fiscalidad internacional, aporta significativamente al contenido técnico de este trabajo académico. Este aporte, antes que un simple análisis crítico de la materia internacional en torno a las políticas fiscales o tributarias de los Estados frente a sus nacionales y residentes, constituye una parada obligatoria a nuestra realidad académica y profesional sobre la situación fiscal y las políticas que la rigen.

Otro de los elementos fundamentales es la revisión y análisis de la aplicación de los convenios en los impuestos directos; para ser precisos, en el impuesto a la renta que gravará su base imponible (es decir el total de activos menos pasivos deducibles). Esto, con el objeto de que una vez evidenciada dicha obligación y los sujetos llamados a su cumplimiento, no resulte más o menos gravoso. Al contrario, se busca que, en ejercicio de los principios internacionales de la tributación (igualdad, generalidad, capacidad contributiva, suficiencia recaudatoria, no discriminación y no doble imposición) exista un ejercicio de cultura tributaria en pro del reconocimiento de los derechos del contribuyente. Todo esto sin que se generen perjuicios al fisco, es decir, a través del establecimiento de mecanismos adecuados que adviertan la existencia de una verdadera cultura tributaria. Es importante resaltar los aportes que sobre esta referencia se hacen en la obra, en cuanto a los criterios que ineludiblemente deben constar en estos CDIs respecto al ejercicio de la potestad tributaria, es decir, la sujeción personal y la sujeción económica, estableciendo que la primera deberá 
partir de los conceptos de nacionalidad y residencia y la segunda de los conceptos de sede de negocios y del principio de fuente.

La referencia de que irremediablemente se debe partir de modelos tipo, dada su trascendencia y aplicación internacional como medios consuetudinarios, hace ver el importante rol que juega en este proceso el modelo de la OCDE y aquel de la ONU, los cuales logran adaptarse, según el caso, a la realidad de los países suscriptores de CDIs. Esto permite a los países negociar las cláusulas a la luz de los textos y sugerencias de los modelos de convenios, siempre y cuando las mismas no vulneren su legislación nacional. No podemos olvidar que en el caso particular del Ecuador los convenios internacionales, antes de su suscripción, pasan por procesos rigurosos de discusión y aprobación que de ninguna manera suplantan o superan los requisitos inevitables de control de legalidad y constitucionalidad por los que deben atravesar para revisar su legal cumplimiento y, por tanto, su conveniencia.

Otros de los elementos ampliamente discutidos y explicados de manera clara por los coautores de la obra es la concepción de los principios de fuente y de residencia. Al determinar que uno de los elementos más discutidos para la imposición tributaria será: ¿qué principio deberá de aplicarse para la generación de la obligación tributaria?, partiendo de la naturaleza del hecho generador, pero también determinando efectivamente dónde se ha generado la obligación tributaria de pagar y aquella de declarar y trasladar lo percibido o retenido.

Se puede advertir que la obra realiza importantes aportes a la academia tributaria al explicar cómo los fundamentos de los CDIs, como métodos para eliminar la doble imposición internacional, radican en la distribución del poder tributario, lo que incluso ha sido entendido por varios tratadistas como una cesión de soberanía fiscal entre los Estados.

En varios pasajes de la obra se realiza un análisis comparativo de los puntos fundamentales entre los modelos de convenios para evitar la doble imposición de la OCDE y de la ONU. Así, se habla del reparto internacional del poder tributario, cuando todo se subsume a principios de reciprocidad advirtiendo la preponderancia que se da al gravamen del Estado de la fuente y el residual del país de la residencia; y, del objetivo común de la lucha contra la evasión fiscal internacional. Estas comparaciones hacen mucho más interesante la lectura que, aunque técnica y árida para muchos, ilustrativa y veraz desde todo punto de vista.

Tan enriquecedor resulta el basarse en esta fuente de consulta, en términos de cultura tributaria internacional, que se puede evidenciar cuándo se generan conceptos tan específicos, como el de establecimiento permanente (EP), en materia tributaria (p. 191). Así, se evidencia lo crucial que resulta determinar con exactitud el tiempo de realización de una actividad económica en un país distinto al de la residencia, como elemento para que se configure un establecimiento permanente.

Sin perjuicio de los criterios que aplique un Estado para determinar la configuración de un establecimiento permanente, el Estado donde se ha producido la actividad económica por ese lapso deberá aplicar los correspondientes CDIs, para definir la generación del gravamen tributario sin que se denote un efecto de doble imposición. Para esto se deberá observar, en primer lugar, si efectivamente se cuenta con un CDI con el país de residencia y cuáles son las normas acordadas entre los países en cuanto al establecimiento permanente.

En lo referente a las condiciones para determinar de adecuada manera la condición de establecimiento permanente, la obra contiene aportes sustanciales al abordar la autonomía de esta figura.

El EP es ampliamente debatido y conceptualizado para poder llegar a conclusiones importantes, como que el EP no tiene una independencia jurídica respecto de la casa matriz 
o "head office" (CM) ni de otros establecimientos permanentes. De hecho, el EP es como una extensión de la casa matriz actuando en otro Estado, tanto es así que se respalda dicho criterio con la distinción y conceptualización de EP, con considerar al EP como parte del resto de la empresa; y, con el criterio de entidad separada. Cuán importante resulta para nosotros como lectores, contar con doctrina de esta magnitud, abordando temas de este talante y tan poco tratados en el Ecuador.

La perspectiva doctrinaria, académica y técnica de los autores ecuatorianos nos hace ubicarnos en nuestra realidad y observar lo adecuado que es el conocimiento y la profundización de este tipo de temas tan técnicos y, en muchas de las ocasiones, muy espesos en conceptos especializados que son conceptualizados de manera eminentemente didáctica en esta obra de fiscalidad internacional. Por ejemplo, criterios como rentas pasivas que se pueden definir como aquellas que se generan cuando un determinado capital incursiona en una actividad económica, generando ingresos por sí solo en el desarrollo de dicha actividad. Así también, el intercambio de información constituye una práctica esencial para llevar adelante muchas de las acciones que desarrollan diferentes actores de la economía.

Otro de los elementos importantes que se abordan en esta obra, es el abuso de los CDIs por cuanto los mismos, aprovechados de manera inadecuada, generan abusos en el efecto de evitar la doble imposición. Como lo refieren los autores, estos esquemas generalmente buscan que residentes de terceros Estados u operaciones no cubiertas accedan al ámbito de aplicación de un convenio que en principio no les sería aplicable, mediante estructuras de planificación fiscal artificiosas como: 1.- Gastos sin sustancia económica; 2.- Ocultamiento del beneficiario efectivo; 3 Treaty Shopping: Uso de un país con el cual Ecuador ha suscrito un convenio para evitar la doble imposición para triangular operaciones.

En el Tratado se realiza un análisis muy importante respecto de la esencia económica sobre la forma jurídica, como una práctica adecuada de norma anti-elusión. Esto se lo realiza a través del artículo 17 del Código Tributario Ecuatoriano que establece la calificación del hecho generador y determina, de manera expresa, en su segundo inciso lo siguiente: "[c] uando el hecho generador se delimite atendiendo a conceptos económicos, el criterio para calificarlos tendrá en cuenta las situaciones o relaciones económicas que efectivamente existan o se establezcan por los interesados, con independencia de las formas jurídicas que se utilicen”.

Esto deriva indudablemente en un análisis respecto de la conveniencia de la implementación de cláusulas de carácter general en los CDIs para que no se desnaturalicen con mecanismos elusivos o evasivos. Sin embargo, esto conllevaría a una reforma integral de todos los convenios bilaterales y multilaterales con la inclusión normas anti-abuso específicas como la cláusula de limitación de beneficios.

Las cláusulas anti-abuso en los CDIs son normas específicas, destinadas a contrarrestar conductas consistentes en operaciones de elusión en el ámbito de la planificación fiscal. Se ilustran como los mecanismos que consiguen dicho objetivo limitando el poder tributario de uno de los dos Estados, especialmente de manera general el Estado en el principio de la fuente, otorgando la competencia para gravar determinadas rentas exclusivamente al Estado con principio de residencia.

La obra nos lleva a realizar varias reflexiones de carácter técnico tributarias y de manera formal. Enfocados en la legislación tributaria ecuatoriana, se ha incluido una cláusula anti-abuso general, en el sentido de que se atienda a la esencia económica con prioridad sobre la o las formas jurídicas utilizadas, cuando la calificación del hecho generador del tributo analizado responda principalmente a elementos y conceptos económicos que conlleven a eliminar las prácticas inadecuadas de contribuyentes en actividades simuladas o supuestas. 
Se da preponderante importancia a la planificación tributaria al definirlo como un elemento que busca minimizar la correspondiente carga fiscal, constituyéndose en uno de los principales objetivos que tienen los administradores de las empresas, para determinar obligaciones tributarias justas y adaptadas a la legislación internacional y a los tratados internacionales.

Los precios de transferencia en el Ecuador se encuentran enmarcados en una Ley y regulados por un reglamento, resoluciones y fichas técnicas para la normal aplicación de los precios de transferencia.

El análisis del "sexto método" será "un método" de determinación de precios de transferencia si con su aplicación logra obtenerse, respecto de los bienes comercializados, el valor que hubiesen fijado partes independientes. Por ello, deviene en imprescindible los cuestionamientos de que si su aplicación garantiza, en todos los casos, la obtención de un precio arm's length.

Se explica y se hace comprender al lector que, la subcapitalización consigue entenderse como el fenómeno mediante el cual una empresa local o domiciliada en un país obtiene un financiamiento externo de su casa matriz o compañía vinculada, aplicando a esta operación el pago de intereses financieros a los cuales los reconoce como gasto deducible dentro del cálculo del impuesto a la renta.

El documento BEPS es un avance importante en la búsqueda de reglas internacionales, aunque su alcance puede y debe ser más limitado de lo que se pretende, su vocación internacional encuentra un problema de legitimidad. A pesar de que surge del impulso del G-20, la OCDE sigue adoleciendo de falta de legitimidad internacional al representar sólo a una parte de los Estados. A decir de los coautores de esta obra de fiscalidad internacional, también para nuestro país la trascendencia de BEPS se explica porque demuestra, por un lado, la necesidad de avivar el debate sobre una disciplina que cuenta con pocos cultores en el medio y, por otro lado, debido a que implica el cambio de paradigma de lo que antes se tenía parcialmente comprendido. Es decir, cuando el país recién empieza a apropiarse de conocimientos y estrategias especializadas propias de la fiscalidad internacional, nuevamente cambian las reglas y condiciones a remolque de proyectos impulsados especialmente por países más avanzados en función de sus intereses recaudatorios y de control de sus residentes.

El objetivo principal de darle a los fideicomisos mercantiles la posibilidad de que tengan personería jurídica, obedece específicamente a una necesidad de control tributaria. Desde el punto de vista tributario el fideicomiso es considerado una sociedad, en tanto que, las operaciones internacionales de las compañías de Telecomunicaciones abren una puerta a la incorporación de prácticas que están al límite de la planificación tributaria, y que como se ha podido señalar, la misma Administración Tributaria Nacional las considera como evasivas, tanto es así que se han establecido glosas.

La tributación de las industrias extractivas es compleja, porque existe participación de compañías multinacionales y de administraciones tributarias de varias jurisdicciones. Las compañías multinacionales tratarán de maximizar sus beneficios a nivel global y los gobiernos tratarán de asegurar sus ingresos fiscales.

Dada la naturaleza misma del comercio electrónico, como en ninguna otra rama y como nunca antes, se hace necesario que existan convenios internacionales para evitar la doble imposición. Generar espacios de diálogo en cuanto a si un Estado, en forma individual, va o no va a poder regular la fiscalidad en el comercio electrónico sin que obligatoriamente surjan conflictos por doble imposición, es la pregunta que se plantea y responde en la obra. 
Ante la dificultad de establecer legislación nacional al respecto, se ha tratado de actuar bajo principios generales, que sirvan de guía para cualquier regulación estatal, de tal manera que se evite que se tomen medidas que impidan el desarrollo del comercio electrónico y puedan generar beneficios o gravámenes excesivos.

Todos y cada uno de los elementos desarrollados en esta breve reseńa que, en lo personal no creo haga honor, en lo más mínimo, a lo que la obra efectivamente aporta a todos los tributaritas ecuatorianos e internacionales, inevitablemente conllevan a la lectura integra del "Tratado de Fiscalidad internacional para el Ecuador" por su envergadura y talante académico, técnico y doctrinario. 